\title{
Health Equity Column: Leading with Health and Racial Equity in the NICU: A Neonatologist Perspective
}

Jenné Johns, MPH, Dalia M. Feltman MD, MA, FAAP

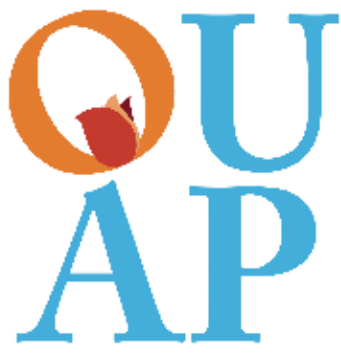

What is your definition of health equity?

In the neonatal and perinatal kind of patient world, not everyone is coming from the same baseline level of health. We know that Black Moms have much higher rates of some of the morbidities that come with being pregnant and that they also have increased rates of dying in the first year after delivery or around delivery. Clearly, there's something going on with baseline health and maybe help at that intersection when they're actually delivering. Maybe there's more that needs to be done as far as listening to Moms and symptoms.

\section{"We know that Black Moms have much higher rates of some of the morbidities that come with being pregnant and that they also have increased rates of dying in the first year after delivery or around delivery. Clearly, there's something going on with baseline health and maybe help at that intersection when they're actually delivering."}

However, they're also coming in, sometimes not as healthy. Because of that, other factors, and the wearing down on health from structural racism and other social determinants of health, it makes it really hard to hope for an equally good outcome for their babies because obviously, the baby's health depends on Mom's health. We know Black Moms are more likely to deliver prematurely, and within those premature newborns, the group I study, extremely premature newborns, are also more likely to be born to Black vs. White Moms.

For me, health equity means trying to get everybody, parents, mostly Moms, because their health is mostly in this. However, Dads' mental health is important as well. Moms and babies [are] coming out with equally good levels of health, and knowing that for the people that aren't coming in with that same higher baseline that they're probably going to need some extra attention.

There's an image of health equity that shows nicely that it doesn't mean equal. For example, you don't give everybody a walker. Everybody does not need a walker to walk. Some people just need a brace; some people need a wheelchair; some people need a cane to get to that same level of health, which would be ambulating and getting around in their daily lives. Thus, it has to be customized for each family.

Our families come from different levels of privilege. There are families that know how to advocate for themselves really well, and they get heard almost immediately. There are also the families that sometimes aren't even able to be there physically, maybe because mom is still really sick, or mom is at home taking care of other kids or doesn't have the transportation. Maybe mom's there, but she really can't effectively communicate. Although we have translators, it's just not the same as when you can just kind of chitchat and talk with a mom if they don't speak English.

What are your organizational priorities for addressing health and racial equity in perinatal and neonatal care?

I'll explain a little bit about what we've done so far since last June. Well, last year was a very difficult summer in Chicago. That was the time the police that killed George Floyd were arrested

, and there were a lot of protests as well as backward protests. There were obviously protests against police, and there were also protests against the fact that this guy wasn't really killed. Rather, the police were doing their job, and it became such a bombshell and an explosive issue. For some reason, that was an alarm clock. A wake-up call just went off and said, "You know, racism is really alive and well, and we have to do something about it. Enough is enough."

That Sunday, I reached out to some friends that write with me for bioethics and opinion pieces and things like that. I asked if anybody wanted to write with me, and one of them did. We wrote something for the Bioethics Net blog. We brainstormed a title such as "The Time is Now." Basically, it was just a wake-up call to say, "I have to start working against racism as that is the only way we're going to get rid of it; it has to be figured out at every level."

"We formed our Diversity and Health Equity committee and recruited people from our unit so anybody could join. The whole idea was for everybody to be able to be involved, such as our secretaries, respiratory therapists, nurses, or doctors."

In the ICU, which is what we call our NICU, I got together with one of our nurse managers, one of our nurses. We formed our Diversity and Health Equity committee and recruited people from our unit so anybody could join. The whole idea was for everybody to be able to be involved, such as our secretaries, respiratory therapists, nurses, or doctors. My goal was for this to be a space where

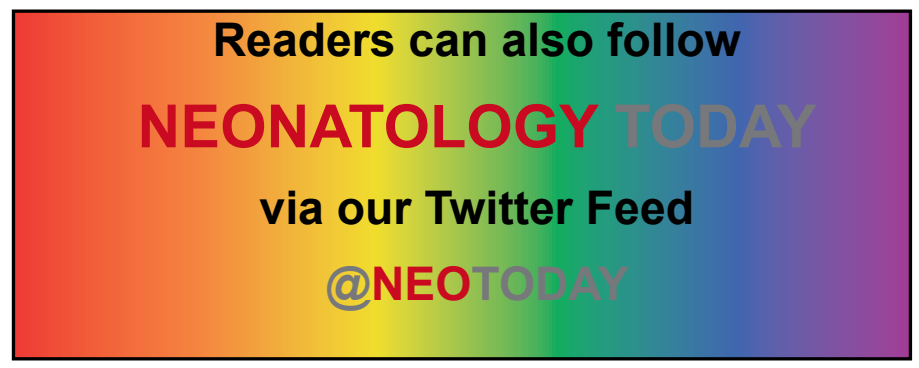


we could get together and talk about this issue because, unfortunately, racism seeps into so many different aspects of people's lives.

Certainly, I'm not in the police force, and what started this whole thing isn't where I would be really doing any work. However, in my brain, at least everyone in their little part of the world could do something. I thought it could be helpful. I'm really happy about our committee. We have worked together. We have two goals. Our first goal is to increase an appreciation and celebration of diversity among our staff and families. The other goal is to work for identifying and making health equity a reality for our family specifically.

\section{"We have two goals. Our first goal is to increase an appreciation and celebration of diversity among our staff and families. The other goal is to work for identifying and making health equity a reality for our family specifically."}

What's been really awesome is that my co-chair and I have had some interesting ideas, but some of them have gone to the wayside because some of our other members have come up with amazing things, things that we hadn't thought of. We've been able to do a lot of interesting things. We have a bulletin board now in our break room so that we can track when we reach our first mission of education and celebrating diversity. We change it out every month. During Black History Month, the nurse takes care of that bulletin board focused on literacy efforts.

One nurse found a local literacy organization that helps bring books that have people of color as characters in the books or celebrate people, historical figures, or celebrity people who have made a difference to help kids be inspired when they read their books. We raised $\$ 1,000.00$ for them. Then, we also put in for a grant from one of our auxiliary boards that have a small grant program. We raised funds, and we were accepted. We are going to be building a library for our parents so that Moms and Dads can check out books and read to their babies to help get Moms and Dads get engaged.

Unfortunately, a lot of times, the Moms and Dads can't do a whole lot if they visit their baby, especially if they're pretty sick, if they're on a lot, or if they're on a breathing machine or I.V.s. They have just a lot of connections, and they need to be in that warm incubator. It's hard to interact with their babies at that point, and they want to be there, and they want to visit. However, they kind of just end up having to sit next to the baby and sometimes just look at the monitor and watch the numbers because, of course, we're always looking at a screen.

We also wanted to provide at least a diverse, nice content library for parents to be able to pull out some books and read to their families. I know Jenné and I have talked about the importance of reading, and she even wrote something about the book that she wrote for her son and that other preemie families can use, which was a lab for preemies. It's called Once Upon Preemie. That's some of the stuff we've done. The other thing is that we have shared opportunities like webinars, interesting research papers that we've come across, and articles for our members to be able to learn more about other equity efforts.

One of those was the Once Upon a Preemie webinar that was "live" and offered last year. That's how I came to learn about the Once Upon a Premium Academy. We were fortunate enough to participate. I wasn't able to watch all of the webinars, but two of them that I watched were excellent. When the CME emails came out, I just emailed Ms. Johns and said, "Thank you for this opportunity. It was excellent." She and I met. She reached out to me to see if I wanted to talk about this, and then it was clear. I told her a little bit about the stuff that we were doing already, and she asked if I could talk maybe about that in the Academy.

It just does a very nice turn of events that I was able to join the faculty. I shared with her that one of the talks that we had seen by one of the Moms, Shanté Nixon, had kind of inspired those of us who had seen it to start working on some other ways to really empower parents to speak up because the people that know how to speak up do it just fine. They usually get what they need. However, it's the Moms that maybe don't feel like they can speak up, or they want to speak up, but they don't exactly know how in this weird setting because most people are not medical. This is a very different environment for anyone to be in. We made a document that gave some hints about how to speak up.

It was Pride Month in June. On our bulletin board, we had some articles and some nice things from the corporate diversity committee. Diversity efforts had been set up on how to speak respectfully and appropriately; for example, people who may prefer certain pronouns. What we did is customize it to our NICU families. We talked about transgender parents having babies, lactation support, and things like that.

\section{"Diversity efforts had been set up on how to speak respectfully and appropriately; for example, people who may prefer certain pronouns. What we did is customize it to our NICU families."}

That's what we're trying to do. We're trying to make it take that general idea of equity and diversity and bring it home to our everyday work lives, which is in our unit, and that is where the issue resides. Basically, my priority is empowering Moms so that they can partner best, and we can partner with them in a meaningful way to care for their babies. We have to know what questions to ask and listen only to Mom's answers. That might not just mean listening to the Moms that are always there and talking to us. It might mean figuring out ways of better communicating with the Moms that, as I said before, have some barriers to engaging, communicating, and interacting, including looking at our own biases. We can figure out we can get implicit bias training. However, once you even know you have a bias, you still have to know how to deal with it and how to interact with Moms. I keep saying Moms, but I really want to get Dad involved, too. I do mean Dads when they're available as well. However, the Moms are a little bit higher priority just because their health is often intertwined with the babies to their physical health. Then another way to really help meaningfully engage is to have a diverse medical team. So that's something else that we just brought in, a speaker who is a first-generation college student.

She talked about the website that she and some other first-generation college students (and are now first-generation medical students). They have made a website for helping people who are looking into medical school. She gave us some statistics that I was not aware of, including there was a large proportion of medical students who already have a parent that's a physician. There's a lot of familiarity for some people that give them privilege and 
makes it a lot smoother process and probably perpetuates the fact that we don't have a diverse workforce and that we do need fresh voices who don't come from a family where everybody has been a doctor. Thus, those are my priorities.

It's unfortunate that it took very unfortunate circumstances to make me realize, "Oh, that's the wake-up call," but hopefully, good things will come out of a bad situation. COVID was just this horrible illustration of the fact that, yes, health equity is not present. There are total inequities that need to be addressed. Maybe for those who have been studying it since college, they know about it. However, I think for other people, it was like, what the heck? Then there are other people that don't believe it, and that's very infuriating. In fact, Black Lives Matter makes people upset, and that makes me upset.

"COVID was just this horrible illustration of the fact that, yes, health equity is not present. There are total inequities that need to be addressed. Maybe for those who have been studying it since college, they know about it. However, I think for other people, it was like, what the heck? Then there are other people that don't believe it, and that's very infuriating."

\section{What personal and professional experiences led you to focus} on health equity in perinatal and neonatal care?

Personally, my family is transracial. I have two internationally adopted children, my husband is white, and my children are Asian and Latino. That said, we've always talked about racism. I've been very cognizant of the way life might be different if I were not white. l've been a little bit more sensitive to issues from that standpoint. I thought, okay, we're going to deal with this as a family. That's one level, and then another level is at work in the unit. What can we do?

Professionally, I'm a bioethicist. So, writing to bioethicists is one part of my life, and then another part of my life is my research. In my research, I am already looking at families' experiences. Because of the nature of our preemies, a lot of them are Black and Brown babies. For this reason, I could kind of focus on that a little bit in a different little lens, but I felt like that was already being taken care of.

My bioethics research is mostly about how families make decisions for when they're facing the prospect of delivering an extremely early newborn. That has led me into a deeper appreciation for what families are going through, the decisions they are making, and really the expertise that they bring that doctors don't bring to the decision-making.

The idea of shared decision-making is that the doctor's kind of lens is supposed to help families figure out the best options for their family and how they see the best interest for their baby. They tell us what we should do; that's easier said than done. I'm researching different kinds of tools and ways to actually make those conversations effectively happen instead of the usual model where factors just come in, lay out a bunch of information, and then say, "Well, what would you like?" I think that's really hard for families who were never even expecting to be in the hospital and thinking about delivering at such an early age. More recently, l've kind of used that family experience and the idea of amplifying voices. When we look at families in the NICU, there are a lot of the voices that really need help being amplified or listened to in an effective way.

What is your call to action for the industry as we seek to eliminate health and racial inequities in perinatal and neonatal care?

I am heartened by the efforts of different departments like O.B., social work, and at the corporate level to try to address racism and health equity from different aspects. Many efforts right now to improve equity are grassroots and voluntary, done on borrowed bandwidth. I see that with our nurses and doctors in our Diversity and Health Equity committee. Time is money-financial support for time to allow work in this area is important. Corporate efforts are necessary but should include supporting work at the level of the medical team/patient, for example, in the NICU.

In neonatology, we have a unique relationship that needs attention at the unit level; we need to partner with parents to help the babies, who are officially our patients. However, a healthy baby needs a healthy Mom, Dad, and siblings. We need their expertise as the babies' families, and they require our medical expertise. By networking with others engaged in similar efforts at their units, we can learn from and support each other.

Disclosure: The authors have no disclosures.

NT

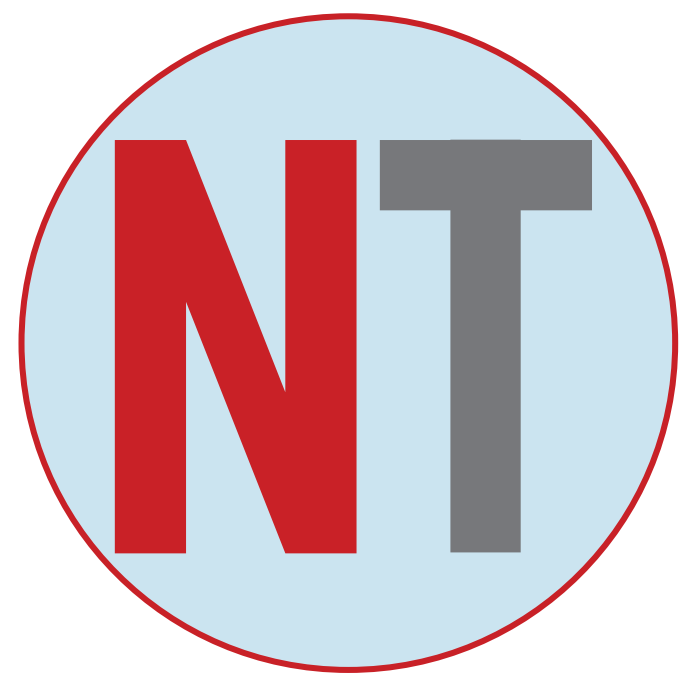




\section{About the Author: Dalia M. Feltman MD, MA, FAAP}

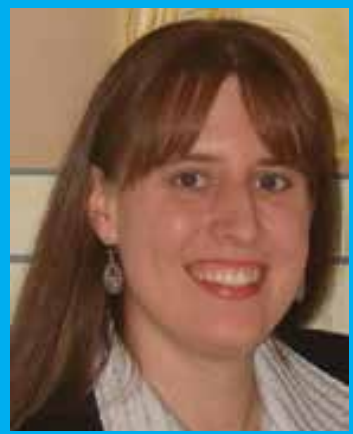

Attending Neonatologist and Clinical Assistant Professor

Attending Neonatologist, Evanston Hospital NorthShore University HealthSystem and

Clinical Assistant Professor, University of Chicago Pritzker School of Medicine

Dr. Dalia M. Feltman is a board-certified neonatologist at NorthShore University HealthSystem Evanston Hospital north of Chicago. She co-founded their NICU's Diversity and Health Equity Committee which works to encourage a culture of mutual respect and to address health

disparities for NICU patients and families. Her fluency in Spanish allows her to appreciate the needs of parents who do not speak English. As a Clinical Assistant Professor at the University of Chicago Pritzker School of Medicine, her teaching sessions focus on communicating effectively and compassionately with families. Dr. Feltman earned her M.A. in Bioethics and Health Policy from Loyola University Chicago's Neiswanger Institute. Using this ethical "lens," Dr. Feltman publishes bioethics research including book chapters and numerous peer-reviewed journal articles and has presented at national academic conferences. Dr. Feltman leads a collaborative study group of researchers from over 15 U.S. training centers called Investigating Neonatal Decisions for Extremely Early Deliveries (INDEED) which studies socioeconomic and medical maternal factors and delivery hospital characteristics with respect to resuscitation decisions for the earliest premature newborns to identify disparities and improve care. Dr. Feltman is a Fellow of the American Academy of Pediatrics, active in their Sections on: Bioethics; Hospice and Palliative Medicine; and Minority Health, Equity and Inclusion.
About the Author: Jenné Johns, MPH:

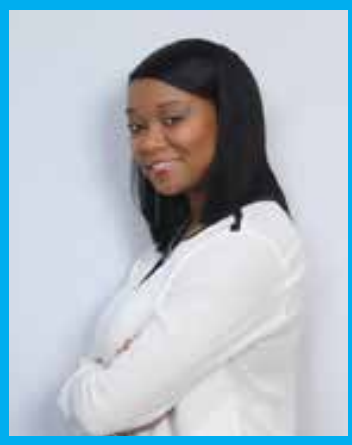

President, Once Upon A Preemie www.onceuponapreemie.com

Founder, Once Upon A Preemie Academy www.onceuponapreemieacademy.com

Jenné Johns, MPH is President of Once Upon A Preemie Founder of Once Upon A Preemie Academy, mother of a micropreemie, author, speaker, advocate, and national senior health equity leader. Once Upon A Preemie is a non-profit organization with a two-part mission: 1.) to donate Once Upon A Preemie books to NICU families in under resourced communities, and 2.) lead virtual health and racial ethnic training programs and solutions to the neonatal and perinatal community through the Once Upon A Preemie Academy. Jenné provides speaking, strategic planning and consultation services for fortune 500 companies focused on preemie parent needs from a cultural lens and reading as a tool for growth, development, and bonding. Jenné is also a national senior health equity thought leader and has led solutionsoriented health equity and quality improvement portfolios for the nations' largest health insurance and managed care companies.

NEONATOLOGY TODAY is interested in publishing manuscripts from Neonatologists, Fellows, NNPs and those involved in caring for neonates on case studies, research results, hospital news, meeting announcements, and other pertinent topics.

Please submit your manuscript to: LomaLindaPublishingCompany@gmail.com 